\title{
Human intestinal capillariasis: diagnosis by jejunal fluid analysis obtained at enteroscopy and reversal of subtotal villous atrophy after treatment
}

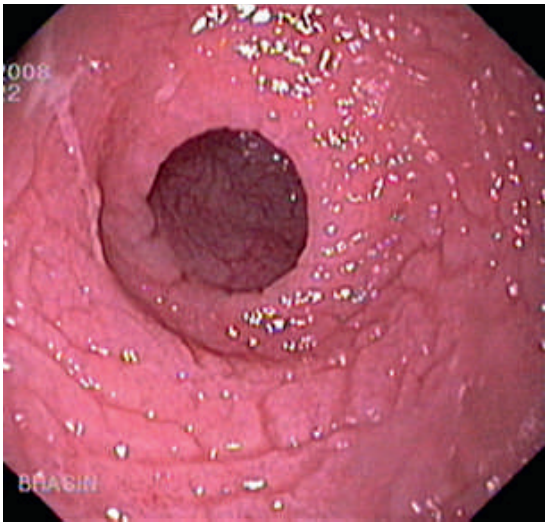

Fig. 1 Endoscopic image showing complete absence of folds in the jejunum with mosaic pattern of the mucosa and white exudates.

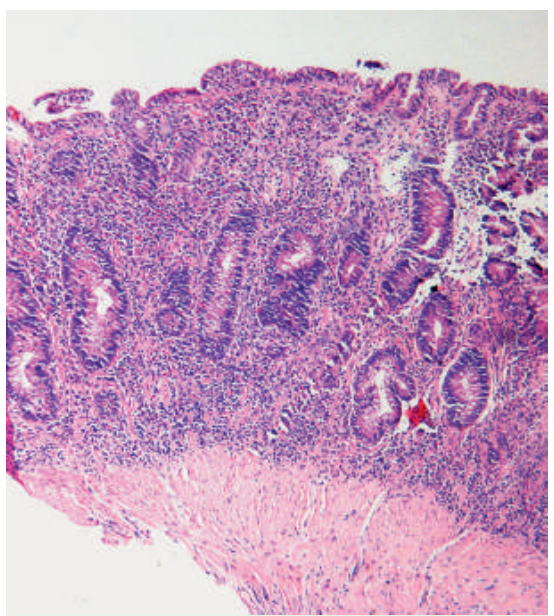

Fig. 2 Photomicrograph shows subtotal villous atrophy (hematoxylin and eosin [H\&E], $\times 20$ ).

A 43-year-old male presented with complaints of watery diarrhea, increasing fatigability, and weight loss. On examination, the patient was malnourished with presence of pallor and pitting pedal edema. Investigations revealed hemoglobin of $9.0 \mathrm{~g} / \mathrm{dL}$ with hypokalemia and hypoproteinemia. Stool examination and rectal swab on multiple occasions did not reveal any pathogenic ova or cyst. Upper gastrointestinal endoscopy, flexible sigmoidoscopy, and duodenal and rectal biopsy were all normal.

Barium follow-through examination revealed an absence of folds in the jejunum.

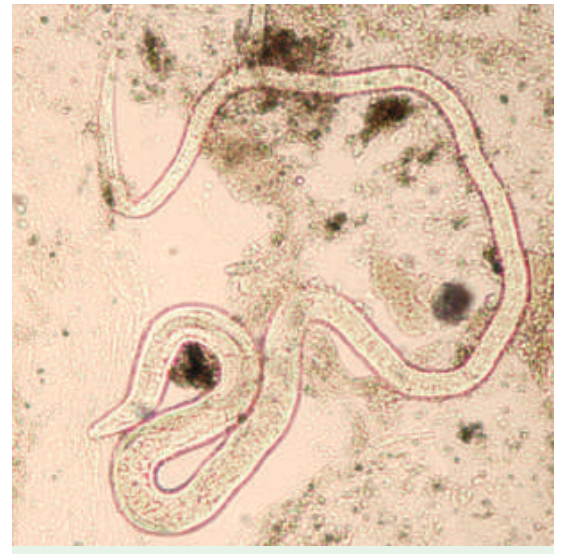

Fig. 3 Photomicrograph shows adult worm of Paracapillaria philippinensis (jejunal fluid).

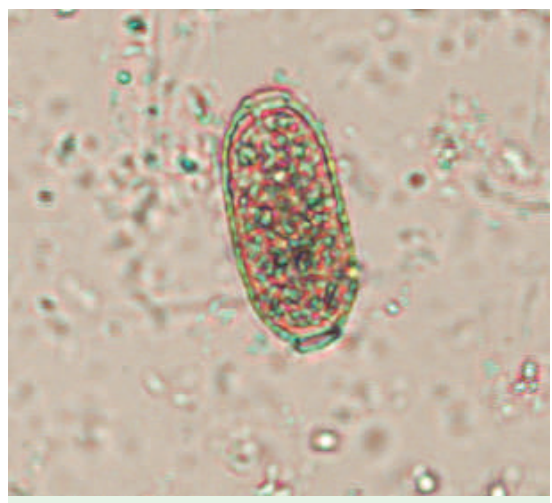

Fig. 4 Photomicrograph shows egg of P. philippinensis (jejunal fluid).

Push enteroscopy revealed complete absence of mucosal folds in the jejunum, with a mosaic pattern of mucosa, focal ulcerations, and presence of white-colored exudates ( $\bullet$ Fig. 1). Histopathologic examination of the jejunal biopsies showed presence of subtotal villous atrophy (๑ Fig. 2) with focal aggregation of eosinophils around a parasite that could not be characterized. The aspirated jejunal fluid showed the presence of an adult worm (๑ Fig. 3), as well as eggs ( $\bullet$ Fig.4) and larva of Paracapillaria philippinensis. The patient was treated with $400 \mathrm{mg} /$ day of oral albendazole for 10 days. He showed marked improvement and started passing normal stools on day 6 of treatment. A repeat enteroscopy performed 3 months after completion of therapy re-

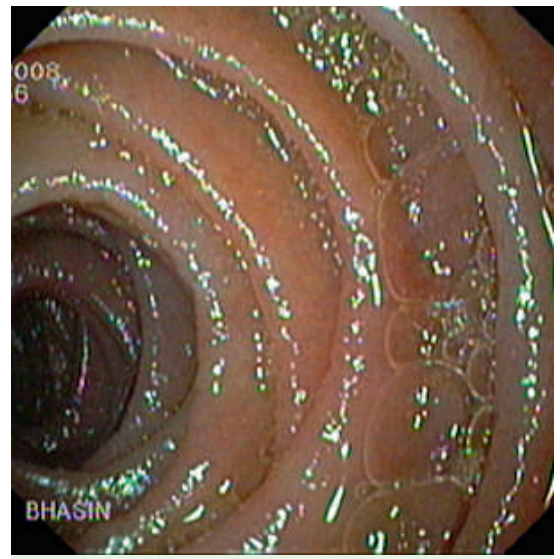

Fig. 5 Endoscopic image: regeneration of folds in the jejunum.

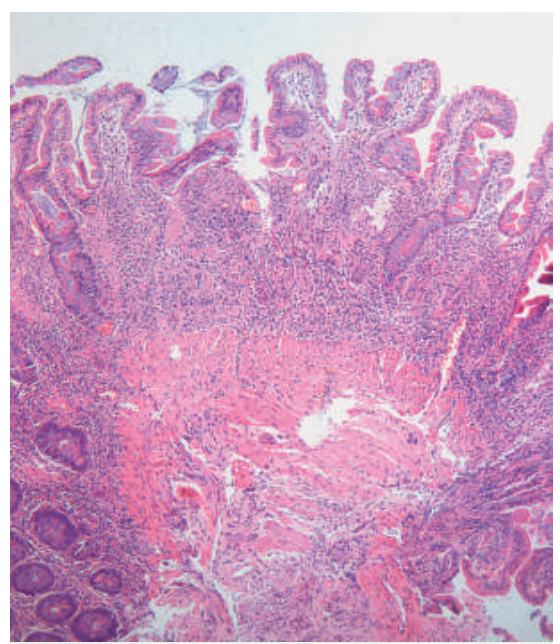

Fig. 6 Photomicrograph shows regeneration of villi $(H \& E, \times 20)$.

vealed normal jejunal folds ( $\bullet$ Fig. 5). The jejunal biopsy revealed regeneration of villi ( $\bullet$ Fig. 6 ).

$P$. philippinensis is a rare cause of malabsorption that occurs as a consequence of eating raw or insufficiently cooked fish harboring the larvae $[1,2]$. As the eggs of $P$. philippinensis are excreted sporadically in feces, multiple stool samples may be required to establish the diagnosis [2]. In cases where stool samples fail to identify the parasite, enteroscopy and jejunal biopsy, as well as microscopic examination of the aspirated jejunal contents can help to establish the diagnosis [2]. 
Endoscopy_UCTN_Code_CCL_1AB_2AZ_3AC

S. S. Rana ${ }^{1}$, D. K. Bhasin ${ }^{1}$, H. S. Bhatti ${ }^{2}$, K. Gupta ${ }^{3}$, R. Gupta ${ }^{1}$, R. Nada ${ }^{3}$, B. Nagi ${ }^{1}$, S. K. Sinha ${ }^{1}$, K. Singh ${ }^{1}$

1 Department of Gastroenterology, Post Graduate Institute of Medical Education and Research (PGIMER), Chandigarh, India

2 Department of Parasitology, Post Graduate Institute of Medical Education and Research (PGIMER), Chandigarh, India

3 Department of Histopathology, Post Graduate Institute of Medical Education and Research (PGIMER), Chandigarh, India

\section{References}

1 Saichua P, Nithikathkul C, Kaewpitoon N. Human intestinal capillariasis in Thailand World J Gastroenterol 2008; 14: 506-510

2 Cross JH. Intestinal capillariasis. Clin Microbiol Rev 1992; 5: 120-129

\section{Bibliography}

DOI $10.1055 / \mathrm{s}-0028-1119609$

Endoscopy 2009; 41: E102-E103

(c) Georg Thieme Verlag KG Stuttgart · New York . ISSN 0013-726X
Corresponding author

\section{S. S. Rana, MD}

Department of Gastroenterology

Postgraduate Institute of Medical Education and Research (PGIMER)

Chandigarh

India-160012

Fax: +91-172-2744401

drsurinderrana@yahoo.co.in,

sonalisurinder@yahoo.co.in 